\title{
PPPUD GITAR SEBAGAI UNGGULAN DAERAH DAN WISATA INDUSTRI KREATIF DI DESA MANCASAN, BAKI, SUKOHARJO, JAWA TENGAH
}

\author{
Wahyu Tri Hastiningsih, Junaedi, A. Anditha Sari, dan Ichwan Prastowo \\ Politeknik Indonusa Surakarta \\ E-mail: wahyutri@poltekindonusa.ac.id
}

\begin{abstract}
ABSTRAK. Berdasarkan permasalahan yang dialami oleh mitra Ari Kustanto, masih belum maksimal produksi, belum adanya merek dagang, belum adanya pengelolaan keuangan, dan pemsaran yang belum maksimal dipasar global. Berdasarkan permasalahan diatas, Program Pengembangan Produk Unggulan Daerah pada tahun pertama akan berkonsentrasi pada bidang peningkatan produksi, pembukuan dan pemasaran. Peningkatan jumlah produksi dilaksanakan dengan cara pemberian bahan bakudan alat produksi yang memadai. Pengelolaan keuangan dilakukan secara komputerisasi dan daring. Begitu pula dengan pemasaran dilakukan dengan menggunakan media daring. (Facebook, Instagram, Website dan marketplace) . Hal ini diterapkan merupakan solusi yang diberikan ke mitra guna menciptakan kualitas dan kuantitas yang maksimal, pengelolaan keuangan yang baik dan terkomputerisasi, merek yang dikenal masyarakat luas.Metode yang digunakan adalah observasi dan wawancara serta pemberian pelatihan mengenai produksi dan K3, pelatihan manajemen keuangan dan pemasaran daring. Hasil dari kegiatan PPPUD ini adalah peningkatan kapasitas produksi, peningakatan asset mitra, publikasi di media cetak Solopos, pembuatan media pemasaran (kartu nama dan nota transaksi penjualan) serta pemsaran daring di Tokopedia.
\end{abstract}

Katakunci: Gitar Mancasan; manajemen keuangan; pemasaran online

ABSTRACT. Based on the problems experienced by Ari Kustanto's partners, production is still not maximaxed, there are no trademarks, there is no financial management, and marketing is not yet maximaxed in the global market. Based on above problems, the Regional Superior Product Development Program in the first year will concentrate on the fields of increasing production, bookkeeping and marketing. Increasing the amount of production is carried out by providing adequate raw materials and production equipment. Finacial management is done computerized and online. As well as marketing is done using online media (Facebook, Instagram, Website and Marketplace). This is applied as a solution provided by partnersto create maximum quality and quantity, good and computerized financial management, branding known to the wider community. The method used is observation and interviews as well as providing training on production and K3. Financial management training and onlinemarketing. The result of this PPPUD activity were increased production capacity, increased partners assets, publication in the Solopos print media, manufacturing of marketing media (business card and sales transaction notes) and online marketing in Tokopedia.

Key words: Guitar Mancasan; financial managemet; online marketing.

\section{PENDAHULUAN}

Desa Mancasan merupakan desa dengan jumlah penduduk lebih dari 6000 orang dan dengan mata pencaharian sebagai petani dan sebagai pengrajin gitar. Pengrajin gitar di desa Mancasan, Baki, Sukoharjo, Jawa Tengah dimulai secara turun temurun sejak tahun 1975. Produk yang dihasilkan tidak hanya gitar, namun alat musik kayu lainnya yaitu ukulele, kajon, alat musik keroncong dan lainnya. Didalam membuat atat musik ini, para pengrajin mendapatkan bahan baku dan alat-alat produksi disekitar tempat tinggal sehingga memudahkan didalam produkstifitas. packaging pun dapat diperoleh dalam bentuk satuan hingga dalam jumlah grosir.

Pengrajin gitar desa Mancasan merupakan pengrajin gitar yang dikategorikan dalam Usaha Mikro Kecil Menengah (UMKM) dikarenakan didalam produksi dilaksanakan dalam satu lingkup dengan tempat tinggal dan masih adanya keterbatasan baik dari segi permodalan maupun sumber daya. Walaupun sumber daya manusia yang digunakan merupakan masyarakat disekitar desa Mancasan, namun masih perlu adanya dukungan motivasi yang kuat. Dalam penelitian sebelumnya, Hastiningsih (2015:50-51), menjelaskan bahwa adanya beberapa factor yang dapat mempengaruhi dalam memproduksi alat musik kayu terutama gitar, yang pertama adalah dari pemilihan bahan baku, peralatan yang digunakan, produksi, finishing dan sistem pelarasan. Yang kedua adalah tenaga kerja yang terlibat hanya merupakan tenaga kerja lepas dengan latar belakang pendidkan SD hingga SMA dan hanya dengan keterampilan turun temurun. Faktor yang ketiga adalah dalam hal pemasaran. Keterbatasan jangkauan pemasaran menyebabkan tidak luasnya pemasaran dan menjadikan harga yang semakin bersaing ketat. Hal ini terjadi pula dikarenakan pemasaran diambil oleh pihak pengepul sehingga profit pengrajin gitar masih rendah.

Hal inilah yang menjadi latar belakang dilaksanakannya kegiatan oleh ketua pengusul melalui Program Pengembangan Produk Unggulan Daerah (PPPUD). PPPUD pada tahun anggaran 2019 ini menggandeng 1 mitra yaitu Ari Kustanto. Dalam hal ini mitra merupakan pengrajin gitar yang mengalami keterbatasan dalam hal permodalan, kapasitas produksi, belum diterapkannya manajemen keuangan dan pemasaran yang masih belum maksimal.

Berdasarkan pada permasalahan yang dihadapi oleh mitra tersebut, maka dapat menyebabkan usaha gitar ini tidak berkembang dengan baik. Untuk itu tim 
PPPUD sepakat untuk menyelesaikan permasalahan tersebut dengan memprioritas pada aspek produksi dengan memberikan penambahan bahan dan peralatan, memberikan pelatihan pembukuan, dan memberikan pelatihan pemasaran meliputi produk, promosi, distribusi dan harga (4P).

\section{METODE}

Kegiatan PPPUD ini dilakukan dengan penyuluhan dan pelatihan kepada mitra. Untuk tahapan sebelum dilakukannya kegiatan ini adalah:

1. Observasi dan wawancara kepada mitra Ari Kustanto untuk memperoleh informasi dan data mengenai permasalahan yang terjadi sehingga dapat memetakan solusinya.

2. Pelatihan secara langsung baik dengan mitra Ari maupun beserta dengan karyawannya sehingga lebih mudah dalam mentransfer ilmu.

\section{HASIL DAN PEMBAHASAN}

Industri gitar yang terletak di Mancasan Baki Sukoharjo telah masuk sebagai usaha unggulan daerah. Hal ini terlihat dari pekerjaan yang dilakukan setiap hari di setiap rumah. Namun sebagai pengembangan usaha terhambat oleh faktor produksi,pembukuan dan pemasaran. Hal ini dialami oleh mitra yaitu Ari Kusnanto. Melalui Program Pengembangan Produk Unggulan Daerah (PPPUD) yang didanai Kemenristek dikti tahun anggaran 2019 ini, penulis mengadakan pelatihan, pengadaan bahan dan alat, perbaikan tempat produksi dan peningkatan produksi pada tahun pertama bagi mitra. Dalam pengelolaan produksi, mitra harus mampu melakukan pengadaan barang untuk bisa memprediksi berapa jumlah produksi yang bisa dihasilkan.Hal ini menurut Hendro yang dikutip oleh Layaman (2016:114) dalam artikelnya bahwa kekurangan dan kelebihan bahan baku produksi akan mempengaruhi proses produksi. Mitra dalam hal produksi memiliki keterbatasan bahan baku serta komponen pendukung. Hal ini bukan karena tidak adanya penjual namun lebih karena adanya keterbatasan dana. Mitra Ari membeli bahan sesuai untuk 1x produksi. Bilamana adanya pesanan dalam jumlah besar, dapat dilakukan namun sering kali tidak sesuai dengan waktu yang telah disepakati. Hal ini karena pembeli hanya memberikan down payment dan akan dibayar lunas setelah pesanan gitar diselesaikan oleh mitra Ari.

Pelaksanaan program PPPUD yang berjalan dari bulan April 2019 ini telah menghasilkan beberapa capaian. Capaiannya berupa pengadaan bahan baku produksi. Bahan bakunya seperti kayu mahoni, kayu maple, kayu sonokeling dan triplek. Alat produksi juga disediakan agar proses produksi berjalan lebih cepat dan efisien. Alat-alat tersebut seperti mesin pasah, grenda tangan, bor tangan dan ekompressor. Penulis juga menyediakan aksesoris pendukung seperti puteran gitar, fred gitar, senar gitar, nut atas dan nut bawah.

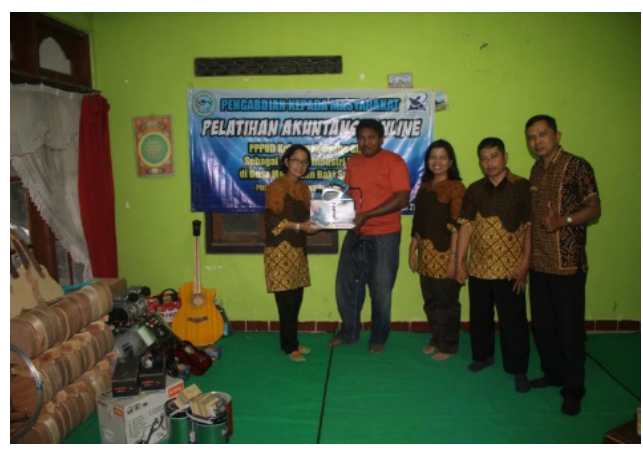

Gambar 1. Penyerahan bahan alat produksi

Dalam proses produksi, keselamatan dan kesehatan kerja (K3) yang ada di mitra tidak mendapatkan perhatian dengan layak. Setiap pekerja produksi dalam melaksanakan produk tidak menggunakan alat keselamatan kerja. Mulai dari pembuatan body, stang, pendempulan body, amplas,cat warna dan finishing. Melihat pentingnya keselamatan dan kesehatan bagi pekerja,maka diadakan pelatihan K3 yang dilaksanakan oleh Ichwan Prastowo. Dalam pemaparannya, Ichwan menjelaskan tujuan K3 dan alat-alat pengaman apa saja yang digunakan oleh pekerja bagian produksi gitar.

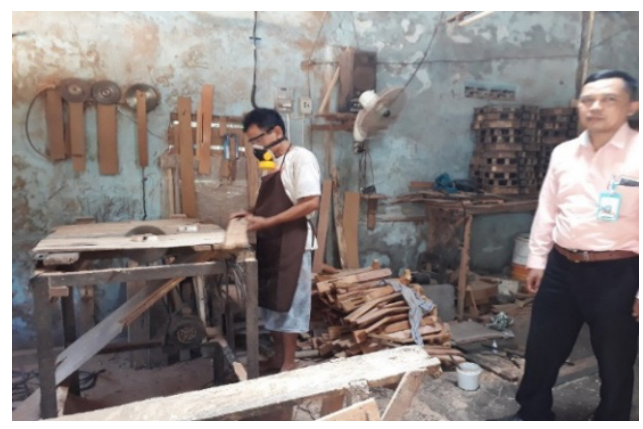

Gambar 2. Pelatihan penggunaan alat K3

Dalam pencatatan administrasi keuangan tidak berjalan dengan baik. Mitra Ari Kusnanto selaku pelaku usaha setiap bertransaksi atau mendapatkan dana (down payment) segera dibelanjakan bahan disekitar tempat tinggal. Nota pembelian bahan oleh mitra berupa body gitar, amplas, cat, dan komponen lainnya tidaklah disimpan dan dicatat. Tidak ada penyimpanan untuk notanota pembelian. Hal ini karena tidak ada personil yang khusus untuk melakukan pencatatan pembelian. Mitra masih mengandalkan daya ingat dikarenakan hal ini telah menjadi kebiasaaan harian. Bila produksi telah selesai, mitra hanya menerima sisa uang pelunasan dan mitra pun tidak melakukan pencatatan di buku khusus. Kondisi ini ternyata tidak hanya dialami oleh mitra. Seperti yang disampaikan Suharni dikutip oleh Setyawati (2018:162) bahwa kelemahan UMKM dalam penyusunan laporan keuangan disebabkan rendahnya pendidikan, kurangnya pemahamam terhadap Standar Akuntansi Keuangan (SAK)dan pelatihan penyusunan laporan keuangan. Sadar akan hal ini,peneliti mengadakan pelatihan pembukuan sederhana dan bisa dilakukan setiap saat 
dengan memanfaatkan android dan laptop. Capaian dalam pembukuan diberikannya pelatihan akuntansi oleh Junaedi selaku anggota melalui aplikasi akuntansi UKM dan cara pembukuan diberikan kepada mitra agar segala transaksi dapat dapat tercatat dengan baik dan rapi dan memudahkan mitra untuk mengelola keuangan secara online melalui aplikasi akuntansi UKM.

Sebagai Mitra, Ari Kusnanto dalam memasarkan produk gitarnya tidak menggunakan merek dagang. Ari berproduksi sesuai dengan pesanan merek dari pengepul atau distributor. Hal ini tentu merugikan Ari sebagai pelaku industri karena produk yang dihasilkan tidak memiliki value dan tidak dapat diidentifikasi. Merek menurut Amirulloh (2017:29) berfungsi sebagai alat promosi produk sehingga masyarakat dapat dengan cepat mengidentifikasi produk kesukaannya berdasarkan merek. Melihat hal ini dengan memperhatikan hal ini adanya perlindungan merek barang-barang yang akan diproduksi oleh suatu UMKM yang berdasarkan UndangUndang No. 20 Tahun 2016 tentang Merek dan Indikasi Geografisberfungsi sebagai alat promosi produk sehingga masyarakat dapat dengan cepat mengidentifikasi produk kesukaannya berdasarkan merek. Capaian dalam hal pemasaran, peneliti bersama dengan mitra menghasilkan merek dagang dengan nama "Java Guitar”.

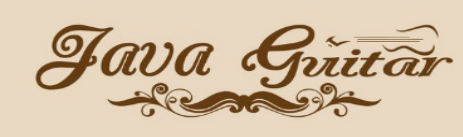

Gambar 3. Merek dagang mitra

Sebagai merek baru tentu membutuhkan media untuk menyebarluaskannya. Media yang telah dicapai oleh peneliti yaitu alat promosi melalui pembuatan kartu nama, pembuatan label dan nota pembelian.Media secara online peneliti bersama mitra telah menghasilkan website di alamat www.gitarmancasan.com, facebook atas nama Ari Kusnanto dan instagram dengan nama Java Guitar dan mendaftarkan marketplace di Tokopedia. Pencapaian yang dilakukan dalam hal pemasaran dilaksanakan melalui proses pelatihan dan pendampingan secara berkelanjutan oleh Anditha Sari.

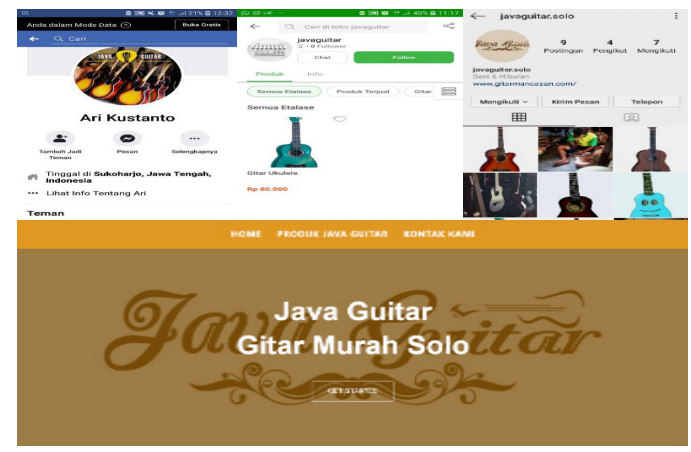

Gambar 4. Media Promosi Online dan market place java guitar
Capaian lain di tahun pertama adalah publikasi di media cetak yang telah terbit di Harian umum Solopos 20 Juli 2019 kolom Sukoharjo Pengabdian masyarakat dengan judul "Politeknik Indonusa Beri Pelatihan Pengrajin Gitar.
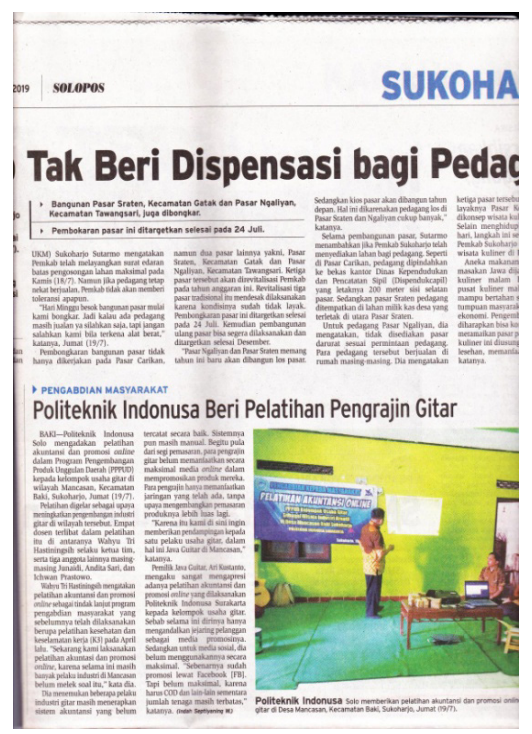

Gambar 6. Publikasi di Solopos, 20 Juli 2019

SIMPULAN

Pelaksanaan Program Pengembangan Produk Unggulan Daerah (PPPUD) yang dilaksanakan mulai bulan April 2019 telah mencapai beberapa target pada tahun pertama yaitu di bidang produksi dengan penambahan bahan dan alat. Bidang manajemen, mitra Ari memperoleh pengelolaan keuangan secara online dengan menggunakan aplikasi keuangan UKM online dan pemasaran. Di bidang pemasaran, mitra Ari diharapkan mendapatkan peningkatan omset dengan mendapatkan pesanan dari marketplace. Harapannya pada tahun ke dua,peneliti bisa ikut serta dalam pameran baik dalam kota maupun luar kota sehingga pemasaran semakin meningkat. Hal ini tidak berhenti begitu saja, namun pada tahun ketiga adanya pemberian dana untuk pengembangan desa sebagai tujuan wisata industri. Hal ini dengan pembuatan showroom bagi pengrajin gitar yang tidak mempunyai tempat. Tidak hanya sebagai showroom saja namun menjadi tempat bagi kelompok pecinta musik sebagai tempat berkumpul untuk menyatukan rasa sehingga dapat ditonton oleh warga sekitar dan harapannya sebagai tontonan bagi wisatawan yang berkunjung. Hal ini sepadan sehingga yang datang tidak hanya membeli gitar namun dapat menonton sebuah pertunjukan musik secara langsung. Perbaikan sarana dan prasana bagi wisatawan yang akan berkunjung dalam hal kebersihan lingkungan sekitar patut menjadi dasar yang penting sehingga dapat menjadi sebuah daya tarik.

\section{UCAPAN TERIMA KASIH}

Kementerian Riset, Teknologi dan Pendidikan Tinggi yang telah mendanai kegiatan Program Pengembangan Produk Unggulan Daerah (PPPUD) 2019; Ir. Suci 
Purwandari,MM sebagai Direktur Politeknik Indonusa Surakarta; Ari Kusnanto sebagai mitra yang telah mendukung kegiatan Program Pengembangan Produk Unggulan Daerah (PPPUD)

\section{DAFTAR PUSTAKA}

Setyawati. Y. (2018). Persepsi Pemilik dan Pengetahuan Akuntansi Pelaku Usaha Mikro Kecil dan Mennegah (UMKM) Atas Penyusunan Laporan Keuangan. Riset Akuntansi dan Keuangan Indonesia 3,(2)
Layaman. (2016). Strategi Meningkatkan Produksi UMKM di Kabupaten Cirebon Melalui Efektifitas Persediaan Bahan Baku dan Modal Usaha.Jurnal Al-Mustashfa, 4 (2), 112-123

Hastiningish. W.T. (2015). Peningkatan Sumber Daya Manusia Pengrajin Gitar Sebagai Industri Kreatif Dukuh Kembangan Sukoharjo Jawa Tengah. 1, 247-59

Amirulloh. M \& Muchtar. H.N. (2017). Strategi Peningkatan Usaha Melalui Perlindungan Merek Bagi UMKM Sale Pisang.Dharmakarya: Jurnal Aplikasi Iptek untuk Masyarakat, 29-32 